\title{
Temperatures of Thermocouple Reference Junctions in an Ice Bath
}

\author{
Frank R. Caldwell
}

(January 5, 1965)

\begin{abstract}
Errors obtained when using several sizes of ISA Type K thermocouple wires (14 to 20 $\mathrm{AWG}$ ) and of copper lead wires (14 to $26 \mathrm{AWG)}$ at different immersions in a properly prepared and maintained ice bath are given. Variables considered include in addition to the wire diameters and materials, depth of immersion (2 to 9 in.), solid cross section of the Pyrex junction tubes, and type of insulation on the copper lead wires. The wires studied represent the maximum (copper) and the minimum (Chromel) thermal conductivities of any of the normally used thermocouple wires. A small amount of data on platinum is included.

Depth of immersion and diameter of the copper wire are extremely important if a high degree of accuracy is to be attained. The solid cross section of the Pyrex junction tubes and type of insulation used are of lesser importance.
\end{abstract}

\section{Introduction}

A thermocouple used to measure temperature is, from its nature, a differential sensor which actually measures the thermal emf generated as a result of the difference in temperature between its two junctions. It follows then, that the temperature of one of its junctions must be known if the measured emf is to be related to the temperature being measured. This junction is known variously as the "cold," "ice," or "reference" junction; and the fact that in measurements at low temperatures it may be the warmest part of interest in the measuring circuit seems often to make no difference; this is still the "cold junction" to many, in spite of efforts of purists to have it called the "reference," or when applicable the "ice" junction. The other is the "measuring" junction that often similarly is called the "hot" junction. In the discussions that follow, the "reference" or "ice" junction refers to the electrical connection between the thermocouple and copper wires leading to the measuring instrument. This connection is made by mercury in the bottom of a Pyrex tube immersed in a bath of water-ice slush at, hopefully, $0{ }^{\circ} \mathrm{C}\left(32^{\circ} \mathrm{F}\right)$. This is a conventional bath, descriptions of which can be found in the literature $[1,2] .{ }^{1} \quad \mathrm{~A}$ discussion of the makeup of the ice bath including effects on its temperature of using tap or distilled water with tap or distilled water ice is given by McElroy in reference [3].

${ }_{1}^{1}$ Figures in brackets indicate the literature references at the end of this paper.
He warns that the reference junction tubes should be located properly in the slush bath if errors "as serious as 2 to $3{ }^{\circ} \mathrm{C}$ " are to be avoided.

The studies reported herein followed discussions in Committee AE-2, Temperature Measurement Sensing, of the Society of Automotive Engineers, that led to the recommended practice of reference [2]. These emphasized the desirability of evaluating the errors resulting from varying geometries of tubes and wires in the ice bath. Conversely, such an evaluation would provide information on the sizes of tubes and wires and depths of immersion that would lead to certain tolerable limits of errors.

The purpose of this paper is, therefore, to point out and give quantitative information on errors that may arise from misuse of thermocouple reference junctions in ice baths, or on the limiting conditions that will cause an error not to exceed the maximum tolerable. Figure 1 is a sketch of an ice bath of the type used in this investigation.

The temptation to cover the entire field of conventional thermocouple wires has been withstood, and as a result, the data obtained are confined almost exclusively to the ISA type $\mathrm{K}$ thermocouple wires (Chromel $\mathrm{P}$ and Alumel in this case) and copper leads. A few observations were made with platinum wire and copper leads. The data presented thus are applicable to thermocouple elements of the lowest conductivity normally used (type $\mathrm{K}$ ) and also of the highest (copper).

The assumption is made in presenting this paper that the reader is familiar with the basic principles of thermoelectric thermometry to the extent, at least, that he can intelligently apply them to practice. 


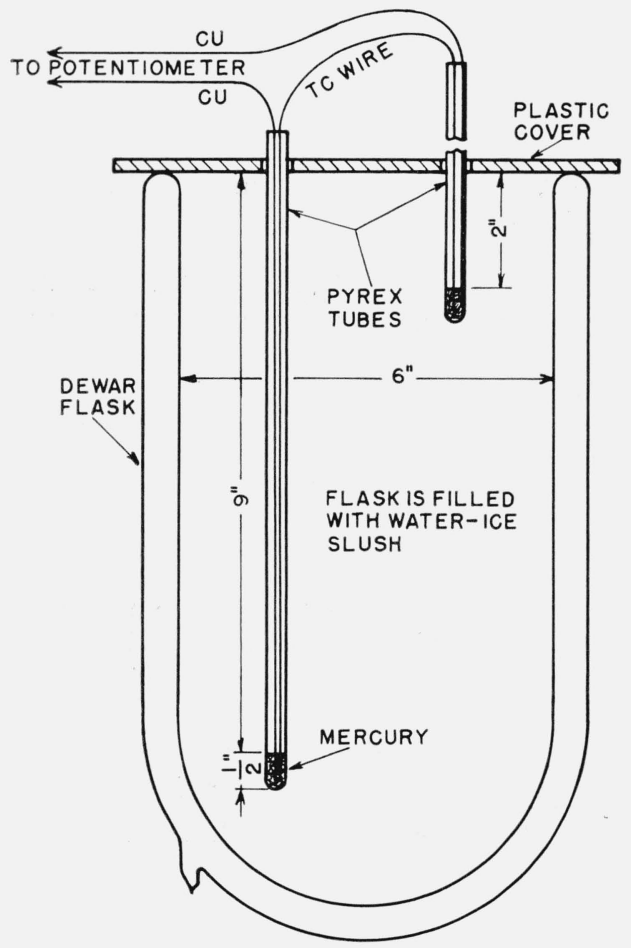

Figure 1. Ice bath and reference junctions.

\section{Practical Considerations}

If one end of a wire is immersed deeper and deeper into a bath of uniform temperature, a depth is reached at which greater immersion produces no further measurable or appreciable change in temperature of the immersed end. When the wire is in a glass tube as considered here and illustrated in figure 1, the same condition is reached, but at a somewhat greater depth. In addition to the depth of immersion, the thermal conductivity of the wires and material of the tubes, cross sections of the wires and tubes, depth of, and immersion of wires in the mercury in the tubes, type of insulation on the thermocouple wires or copper lead wires, and contact of the wires with the sides of the tubes all may affect the temperature at the reference junctions. The condition of the ice bath also is important, and it should be renewed or replenished often enough that no measurable gradient exists in either the vertical or horizontal direction in the area of the tubes.

Within limits, then, several choices are available for reducing the temperature of the reference junction in an ice bath and consequently the error introduced by the difference between the temperature of the junction and $0{ }^{\circ} \mathrm{C}$. The choices examined in this work are: cross sections of wires, of both copper and thermocouple materials; type of insulation on the copper wire leads; immersion of junctions in the ice bath; and cross section of the glass tubes.

\section{Materials and Procedure}

The first thermocouple wires examined were four sizes of Chromel and Alumel (ISA type K): 8-, 14-, 20-, and 26-gage (American Wire Gage). Copper wires used with these were 14-, 20-, and 26-gage. The type $\mathrm{K}$ wires were oxidized, and the copper was enamel-insulated. Each increment between these wire sizes starting with the smallest represents an increase of about twice the diameter and four times the cross section. The dimensions of the several gages of wires used are given in table 1.

TABLE 1. Diameters and cross-sectional areas at $20{ }^{\circ} \mathrm{C}$ of the wires used ${ }^{\text {a }}$

\begin{tabular}{|c|c|c|c|c|}
\hline \multirow{2}{*}{$\begin{array}{c}\begin{array}{c}\text { American wire } \\
\text { gage }\end{array} \\
8 \\
\end{array}$} & \multicolumn{2}{|c|}{ Diameter } & \multicolumn{2}{|c|}{ Cross section } \\
\hline & $\begin{array}{l}\text { in. } \\
0.1285 \\
.06408 \\
.03196 \\
.01594\end{array}$ & $\begin{array}{l}m m \\
3.264 \\
1.628 \\
.8118 \\
.4049\end{array}$ & $\begin{array}{c}\text { in. } .^{2} \\
0.01297 \\
.003225 \\
.0008023 \\
.0001996\end{array}$ & $\begin{array}{l}m m^{2} \\
8.366 \\
2.081 \\
0.5176 \\
.1288\end{array}$ \\
\hline
\end{tabular}

a From Smithsonian Physical Tables (Smithsonian Institution, Washington, D.C., 1954) ninth revised edition; W. E. Forsythe, Editor.

Thermal conductivities of Chromel, Alumel, copper, and Pyrex No. 7740 are given in table 2. Here copper is seen to have over 21 times the thermal conductivity of Chromel P, about 13 times that of Alumel, 5.5 times that of platinum, and nearly 350 times the thermal conductivity of Pyrex.

TABle 2. Thermal conductivities at $0^{\circ} \mathrm{C}$ of copper, Chromel $P$, Alumel, and Pyrex, and of copper and Pyrex relative to the others

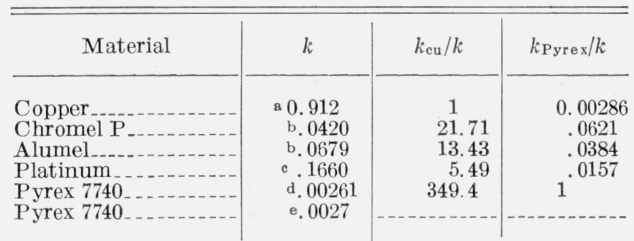

a C. S. Smith, The Physical Constants of Copper, Metals Handbook p. 1380 (The American Society for Metals, 1939).

b Extrapolated from table in Hoskins Manufacturing Company Catalog $\mathrm{M}-61, \mathrm{C}-\mathrm{A}, 1961$, p. 5 , and converted from watts $/ \mathrm{cm}{ }^{\circ} \mathrm{C}$. Chromel and Alumel are registered trade-marks of the Hoskins $\mathrm{Mfg}$. Co.

c Calculated from equation of Holm and Störmer, Measurement of the thermal conductivity of a platinum specimen in the temperature range $19-1020^{\circ} \mathrm{C}$, Wiss. Veroffentlich. Siemens-Konzerns 9, part II, 312 (1930).

d Private communication from T. W. Watson, Building Research Division, National Bureau of Standards, and converted from milliwatts $/ \mathrm{cm}^{\circ} \mathrm{C}$. Pyrex is a registered trade-mark of the Corning Glass Works. This is the value that is compared with those of the alloy and copper wires.

e Smithsonian Physical Tables, ninth revised edition; table 555, p. 534. Note: $k$ is thermal conductivity in $\mathrm{cal} / \mathrm{cm} \mathrm{sec}{ }^{\circ} \mathrm{C}$.

Thermal conductivities of all of the commonly used thermocouple materials are within the range between copper and Chromel. For wires of a particular diameter therefore, copper, having the highest conductivity, may be expected to cause the greatest error; and use of the low-conductivity Chromel alone, if possible, would result in the smallest. This latter condition is not practical, because copper is used almost universally for the lead from the ice bath regardless of the type of thermocouple used. For practical applications of copper 
in conjunction with other thermocouple wires whose combined thermal conduction lies between those of copper and Chromel, the errors also will lie between those resulting from the use of copper and Chromel alone.

The diameters and solid cross sections of the Pyrex tubes used are given in table 3 . Sizes of tubes are identified in the table and in the text by the letters of column 1 .

TABLE 3. Diameters and solid cross-sectional areas of the Pyrex tubes used

\begin{tabular}{|c|c|c|c|c|}
\hline Tube & O.D. & I.D. & \multicolumn{2}{|c|}{ Solid cross section } \\
\hline $\begin{array}{l}\mathrm{I}_{\mathrm{N}} \\
\mathrm{B} \\
\mathrm{I}_{1} \\
\mathrm{D} \\
\mathrm{E} \\
\mathrm{H}\end{array}$ & $\begin{array}{l}\text { in. } \\
0.312 \\
.245 \\
.234 \\
.199 \\
.154 \\
.121\end{array}$ & $\begin{array}{l}\text { in. } \\
0.230 \\
.162 \\
.152 \\
.131 \\
.079 \\
.071\end{array}$ & $\begin{array}{l}\text { in. }{ }^{2} \\
0.0351 \\
.0265 \\
.0249 \\
.0176 \\
.0137 \\
.0075\end{array}$ & $\begin{array}{r}m m^{2} \\
22.6 \\
17.1 \\
16.1 \\
11.4 \\
8.84 \\
4.84\end{array}$ \\
\hline
\end{tabular}

Thermal electromotive force (emf) was measured with a type $\mathrm{K}-3$ potentiometer and a galvanometer with a sensitivity of about $5 \mathrm{~mm} / \mu \mathrm{V}$.

The ice bath illustrated in figure 1 was made in a large Dewar flask with a clear plastic cover, drilled to receive the Pyrex reference junction tubes. This cover was substituted for the often used cork stopper in order that the depth of immersion of the tubes could be measured more accurately. The intended depth of mercury in the tubes was $1 / 2$ in. when the wires were immersed in it. Mercury does not, however, normally wet the Chromel and Alumel wires and so the depth of the mercury often was irregular across the tubes, deeper than $\frac{1}{2}$ in. on one side and not so deep on the other. This effect was greater with the larger wires, and undoubtedly in some cases affected the indicated temperature of the junction between the alloy and copper wires. Although only two tubes are shown in the cross-sectional view of figure 1, observations often were taken with several in the ice bath at once.

All of the results presented herein were obtained in ice baths that were made and maintained according to the directions given in references [1] and [2]. Clear shaved ice and tap water were used, and a water-ice slush filled the Dewar flask at all times during observations. This latter precaution is important in the use of an ice bath, because the water at the bottom of a bath in which the ice is merely floating may be as high as $4{ }^{\circ} \mathrm{C}$, the temperature of maximum density of water. This is not just academic; it has been observed in many instances in which long reference junction tubes have been used in an inadequately maintained ice bath. The junctions in these long tubes that extended through the slush into the water below actually have been found to be at temperatures well above $0{ }^{\circ} \mathrm{C}$, and replenishing the ice bath has corrected conditions.

Use of tap water may, as discussed in reference [3], have some effect on the temperature of the ice bath, and this should be considered in cases where extreme accuracy is required. For the purposes of this paper though, this effect is unimportant; because all observations are differential. The chief requirement here has been that the ice bath be at as nearly a uniform temperature as possible throughout.

The procedure used was to immerse a tube containing one junction of, for example, a Chromel versus copper thermocouple so deeply in an ice bath that further immersion caused no detectible change in the thermal emf. This depth was found for the largest wires, both alloy and copper, and the largest glass tubes used, to be 9 in. or less; consequently, the stationary leg of the thermocouple in all cases was immersed to a depth at which the top of the mercury in the reference junction tube was at least 9 in. below the top of the ice bath. The other leg was immersed initially to a depth of 2 in. above the mercury and, with the thermocouple connected to the potentiometer by copper leads, a reading of the thermal emf was taken. The two junctions and the circuitry are shown in figure 1. The immersion was increased by an inch and another reading was taken. This was repeated for immersions up to 9 in., or to depths at which the emf became zero or constant. In the latter case the constant emf, normally a fraction of a microvolt was taken as an indication of inhomogeneity of the wires, and not a true reflection of a temperature difference between the two junctions. In such cases the constant readings were corrected to zero, and the same correction was added to the readings at all depths.

The first observations taken were obtained by repeating the procedures just described for all combinations of gages of Chromel $\mathrm{P}$ and copper and of Alumel and copper. At least two sets of data were taken in this phase for each combination, and in one case nine sets were taken. Three sizes of Pyrex tubes were used for the variable-immersion leg; the smallest had a solid cross section of about 71 percent of that of the largest. These are the first three sizes of table 3 .

Although the thermal conductivity of the Pyrex reference junction tubes is very low relative to that of Chromel or Alumel, and extremely low relative to copper, separate data were taken to determine the effect, if any, of a change in the solid cross section of the tubes on the temperature of the reference junction.

Another set was taken to find whether or not the type of insulation on the copper lead wires to the reference junction had a measurable effect. In one case the single silk enameled insulation was used with 22 -gage Alumel, and in the other the silk was removed, leaving only the enamel. The same leads were used with a platinum wire 0.020 in. in diameter (24-gage), a commonly used size. The Pyrex tube in each case was $\mathrm{E}$ with a solid cross section of $0.0137 \mathrm{in.}^{2}$ and $0.079 \mathrm{in}$. I.D. This size was chosen as a compromise between the fragility of the smaller, thinner-walled tubes and the larger, more durable tubes of higher thermal conductance. 


\section{Results and Discussion}

Data taken to find the effects of changing size and immersion of the type $K$ and copper wires are presented in figures 2 and 3. Plotted in each figure are curves of emf of one type $\mathrm{K}$ wire of one gage against copper of three gages versus depth of immersion of the reference junctions in the ice bath. Figure 2 is for Chromel versus copper, and the data for Alumel are given in figure 3.

Chromel is thermoelectrically positive to copper, and Alumel and platinum are negative. This means, for example, that the positive Chromel element of a Chromel versus copper thermocouple must be connected to the plus terminal of a measuring instru-
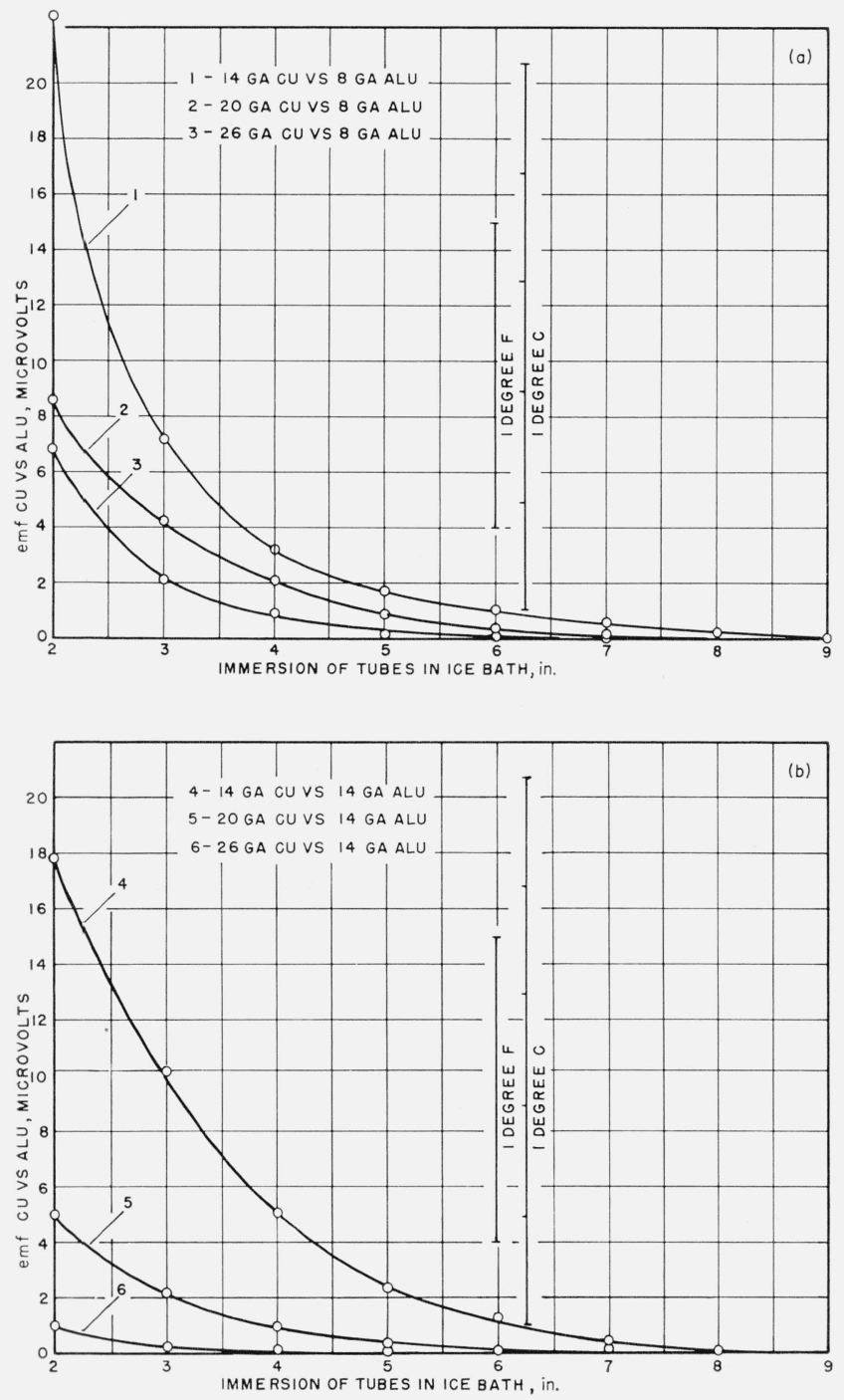

ment in order to get a positive reading when the measuring junction is at a temperature higher than that of the reference junction. Similarly, in the case of a copper versus Alumel thermocouple, the copper must be connected to the + terminal of the measuring instrument.

In the discussions and figures that follow all thermoelectric data are positive, i.e., the thermocouples considered are Chromel versus copper, copper versus Alumel, and copper versus platinum. The thermoelectric power at $0{ }^{\circ} \mathrm{C}$ of Chromel to copper is $19.57 \mu \mathrm{V} /{ }^{\circ} \mathrm{C}\left(10.87 \mu \mathrm{V} /{ }^{\circ} \mathrm{F}\right)$, of copper to Alumel is $19.71 \mu \mathrm{V} /{ }^{\circ} \mathrm{C}\left(10.95 \mu \mathrm{V} /{ }^{\circ} \mathrm{F}\right)$, and of copper to platinum is $6.15 \mu \mathrm{V} /{ }^{\circ} \mathrm{C}\left(3.42 \mu \mathrm{V} /{ }^{\circ} \mathrm{F}\right)$. The following list of abbreviations are those used in figures $2,3,4$, and 5 , and in the tables.
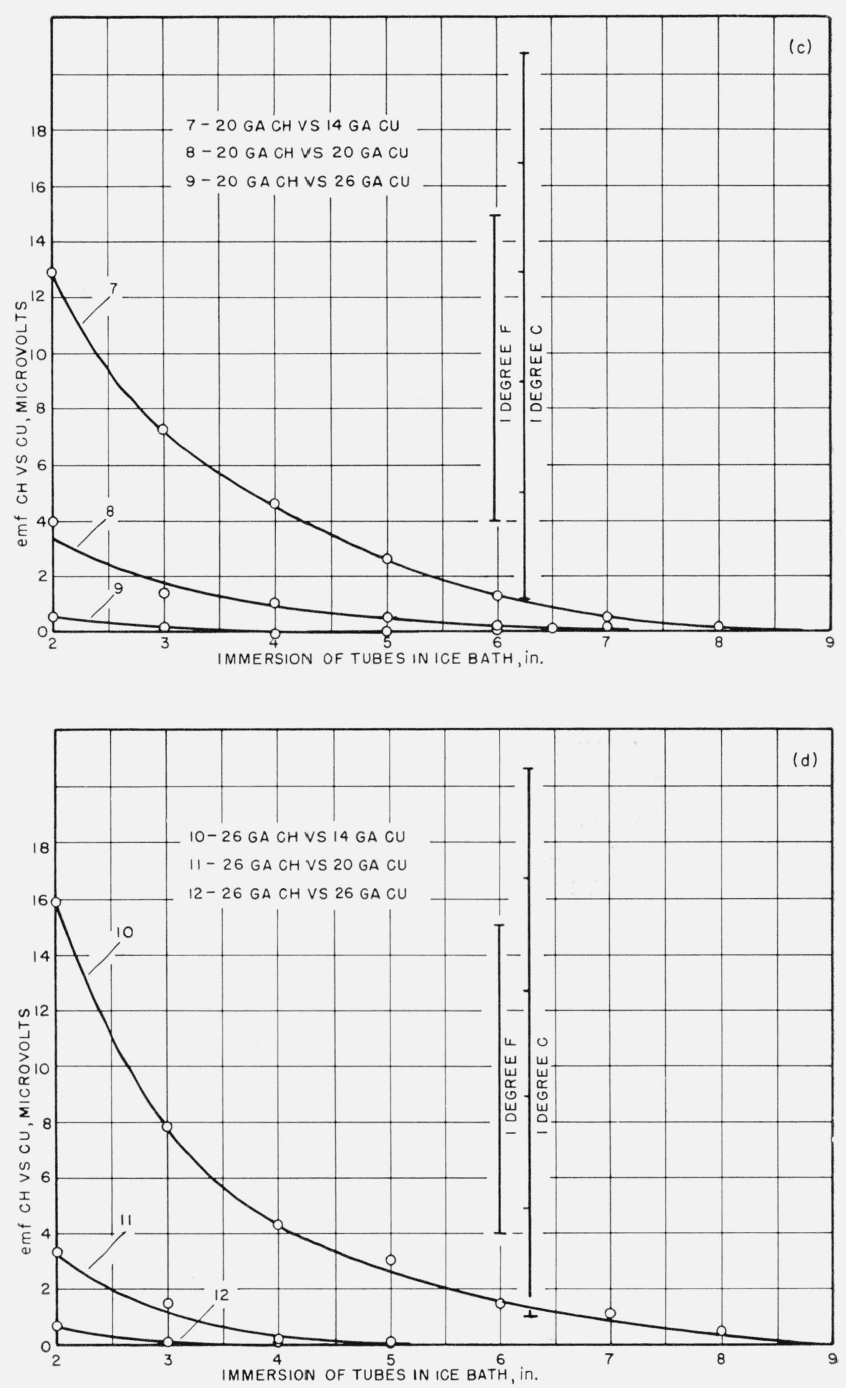

Figure 2. Thermal emf of Chromel versus 14-, 20-, and 26-gage copper at various depths of immersion in an ice bath.

a. 8-gage Chromel.

b. 14-gage Chromel. c. 20-gage Chromel.

d. 26-gage Chromel. 
$\mathrm{ALU}=$ Bare Alumel wire

$\mathrm{C}=$ Celsius

$\mathrm{CH}=$ Bare Chromel wire

$\mathrm{CU}=$ Copper wire

$\mathrm{EN}=$ Enamel electric insulation

$\mathrm{F}=$ Fahrenheit

$\mathrm{GA}=$ American wire gage

$\mathrm{ID}=$ Inside diameter

$\mathrm{OD}=$ Outside diameter

$\mathrm{PT}=$ Platinum wire

$\mathrm{SE}=$ Single layer silk + enamel electric insulation

$\mathrm{TC}=$ Thermocouple
Although the data are somewhat erratic, especially at the lowest immersions, some facts are immediately apparent. As expected, deeper immersion is seen to result in smaller error, or deviation of the temperature of the junction from $0{ }^{\circ} \mathrm{C}\left(32^{\circ} \mathrm{F}\right)$. The error appears generally to be slightly smaller for Chromel than for Alumel, though this is masked in some cases by the lack of precision of the measurements; otherwise the patterns are quite similar.

The most potent variable is seen from the figures to be the size of the copper leads from the ice junctions. The relatively mild changes of solid cross
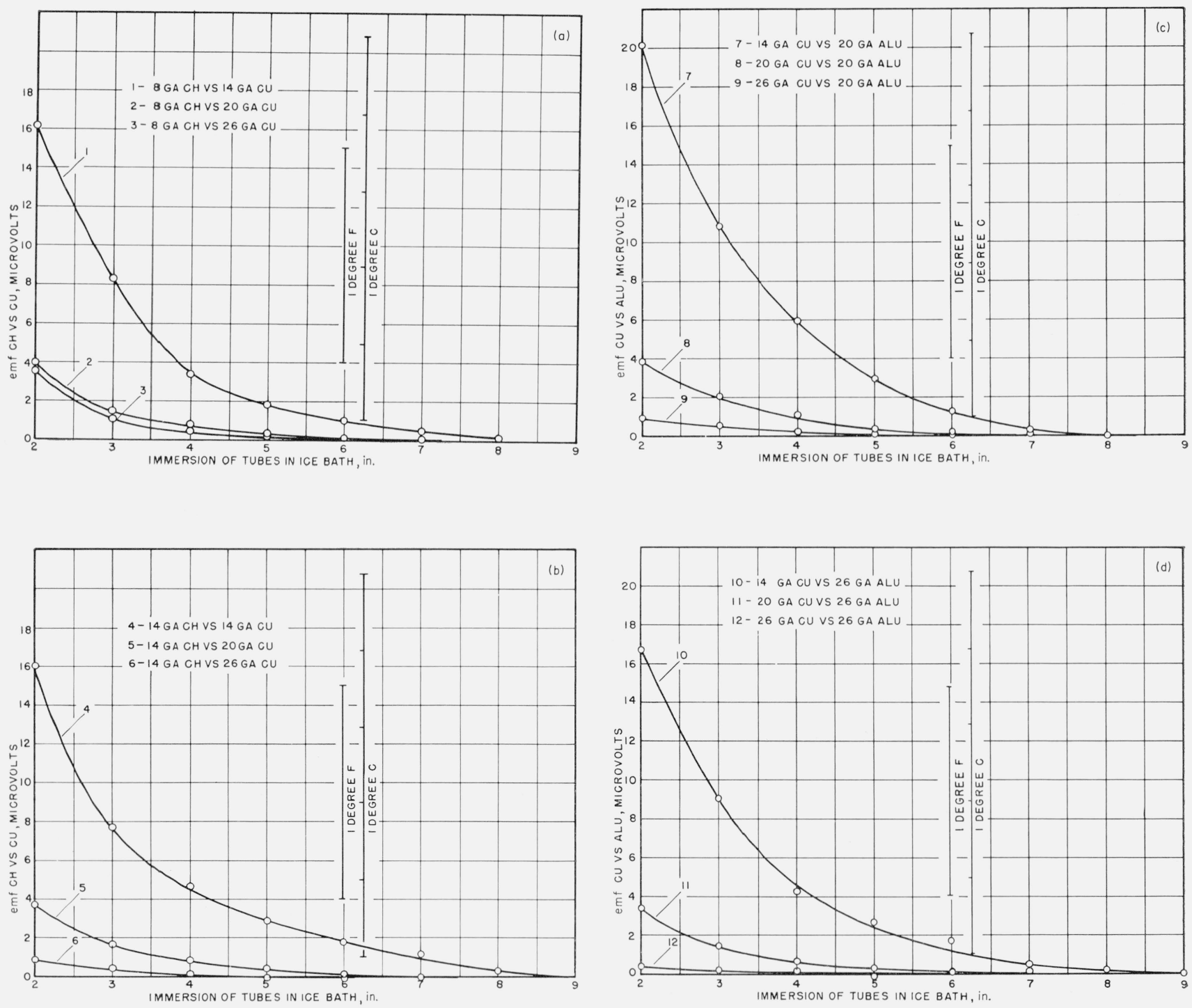

Figure 3. Thermal emf of 14-, 20-, and 26-gage copper versus Alumel at various depths of immersion in an ice bath. 


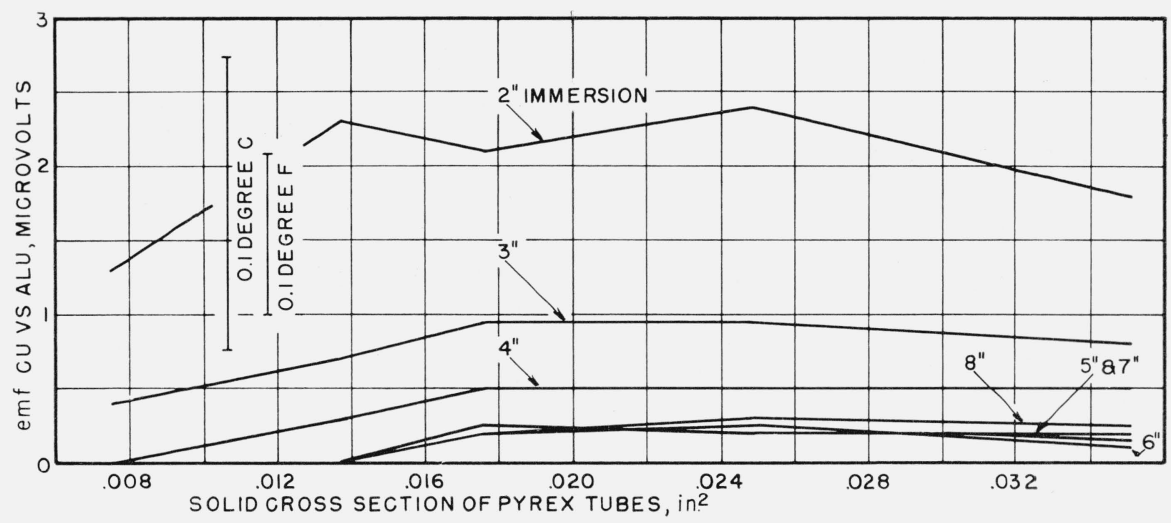

Figure 4. Effect of solid cross section of Pyrex tubes on thermal emf of copper versus Alumel at various depths of immersion in an ice bath.

Copper was 22-gage SE; Alumel was 22-gage.

section of the Pyrex reference junction tubes had no discernible effect. The largest copper wire used, 14-gage, was responsible for an error at an immersion of 2 in. of about $3 / 4{ }^{\circ} \mathrm{C}$ for 8 -gage Chromel and $1{ }^{\circ} \mathrm{C}$ $\left(1.8^{\circ} \mathrm{F}\right)$ for 8 -gage Alumel. At the same immersion and for the 8 -gage type $\mathrm{K}$ wires, 20 -gage copper was responsible for errors of $0.2{ }^{\circ} \mathrm{C}$ or less when used with Chromel and up to $0.4{ }^{\circ} \mathrm{C}$ with Alumel. A depth of 4 in. is sufficient to reduce the error with either Chromel or Alumel of 14 gage or smaller and copper of 20 gage or smaller to $0.05^{\circ} \mathrm{C}$ or less. With two exceptions where the error was $0.02{ }^{\circ} \mathrm{C}$, immersion of the 26-gage copper wire to a depth of 3 in. gave an error of $0.01{ }^{\circ} \mathrm{C}$ or less. The errors resulting from use of copper leads of the latter two sizes at an immersion of 6 in. always are less than $0.01{ }^{\circ} \mathrm{C}$.

The data of figure 4 were taken to determine the effect if any of the solid cross section of the Pyrex tubes on the temperature of the reference junction. The thermocouple used here was copper versus Alumel, both 22 gage; and the 22-gage copper was single silk, enamel insulated. Each curve of the chart is for a specific immersion of the top of the mercury in the tube into the ice bath.

Although the emfs developed here are generally lower at immersions up to 4 in. than are the approximately corresponding values of figure 3 , the curves of figure 4 do point out the relative insensitivity of the junction temperature to the size of the Pyrex tubes used. In using the procedure described earlier to correct for any residual emf, the emf at $9 \mathrm{in}$. immersion was made to be $0 \mu \mathrm{V}$. The emfs at immersions from 5 to 8 in. as a result, then turned out to be from 0.1 to $0.3 \mu \mathrm{V}$ for tube cross sections down to about 0.018 in. ${ }^{2}$ The values for the two largest tubes are bracketed above by those for 8 in. immersion and for 6 in. immersion below. Practically, this latter emf is of such a magnitude that the spread undoubtedly is within the limits of precision of the observations; thus the error over an immersion of from 5 to 8 in. can be considered constant at $0.2 \mu \mathrm{V}$ or so. This corresponds to about $0.01{ }^{\circ} \mathrm{C}$. Another set of data similar to this, but with 26-gage Alumel showed the spread to be from 0 to about $0.5 \mu \mathrm{V}$ for immersions of 5 to 9 in., or about $0.02{ }^{\circ} \mathrm{C}$. The wider spread here, as in some other instances, may have been caused by inhomogeneities introduced by greater cold working of the smaller wire.

Data presented in figure 5 are intended to point out any difference that might result from the use of different types of insulation. Curve 1 (solid circles) is for bare 22-gage Alumel and 22-gage single silk, enamel insulated copper in tube $\mathrm{E}$, and Curve 2 (open circles) is for the same wires with the silk insulation carefully removed. The difference in

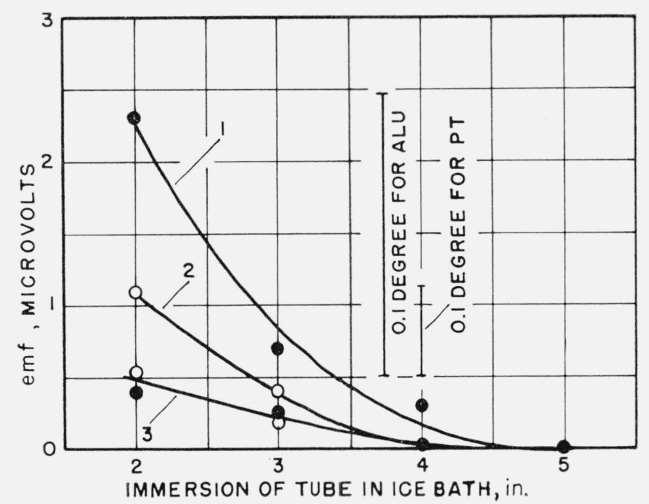

Figure 5. Effects of insulation of copper leads on thermal emf of copper versus Alumel and copper versus platinum at various depths of immersion in an icc bath.

denotes 22-gage $\mathrm{SE} \mathrm{Cu}$, versus 22-gage Alu in curve 1 and versus 24-gage Pt in curve 3 .

denotes 22-gage $\mathrm{EN} \mathrm{Cu}$, versus 22-gage $\mathrm{Alu}$ in curve 1 and versus 24-gage $\mathrm{Pt}$ in curve 3. 
thermal emf at an immersion of $2 \mathrm{in}$. corresponds to about $0.06{ }^{\circ} \mathrm{C}$. Similar observations were taken with copper versus platinum thermocouples. The difference in this case, in the reverse direction, is so small as probably to be within the limit of precision. The one curve (3) drawn through the observations thus can be taken as an indication of errors to be encountered when using 24-gage platinum and a 22 -gage copper wire lead. The error corresponds to about $0.07^{\circ} \mathrm{C}$ at an immersion of 2 in., $0.03^{\circ} \mathrm{C}$ at 3 in., and vanishes at 4 in.

\section{Conclusions}

The foregoing data point out that the errors caused by insufficient immersion in an ice bath, even under the extreme conditions of large wires and glass tubes, can be small enough that they will not be the primary causes of inaccuracy in many cases of engineering measurements. In those cases where the errors are of an intolerable magnitude, use of smaller wires and greater depth of immersion of the junction below the surface of the ice bath can reduce the error practically to the vanishing point. The size of the Pyrex tube used to contain the reference junction can be varied, within reasonable limits, without any appreciable effect on the temperature of the reference junction.
The type of insulation on the copper wire, single silk enamel or enamel alone were seen in the case of Alumel apparently to have a measurable effect on the temperature of the reference junction, but in a similar test with platinum, no such result was found. These results are, therefore, somewhat inconclusive although it does seem reasonable that an effect of the type of insulation used on moderate sized wires should be seen.

\section{References}

[1] SAE Aerospace Information Report No. 46, The preparation and use of Chromel-Alumel Thermocouples for turbojet engines, Committee AE-2, Temperature Measurement Sensing, Society of Automotive Engineers, Inc., 485 Lexington Avenue, New York 17, N.Y., March 15, 1956.

[2] SAE Aerospace Recommended Practice No. 691, Recommended ice bath for reference junctions, Committee AE-2, Temperature Measurement Sensing, Society of Automotive Engineers, Inc., 485 Lexington Avenue, New York 17, N.Y., August 1, 1964.

[3] D. L. McElroy, Progress Report 1. Thermocouple research report for the period November 1, 1956 to October 31, 1957, ORNL 2467. 